\title{
Possibility in the Actual World
}

\author{
Douglas J. Webb
}

\section{Introduction}

If one affirms an unrestricted law of bivalence, then there is a set of present truths that captures everything about the future. To begin, let me explain and briefly criticize (the affirmation of) this law. By 'unrestricted bivalence', I mean the common philosophical position that all propositions are either true or false (a.k.a. not true) including propositions about the future, and all the while ignoring the distinction between internal and external negation. By 'external negation', I mean the negation of an (entire) claim, and by 'internal negation', I mean a claim with a negative predicate. For example, It is not the case that I will score a 1600 the next time I take the SAT test is an external negation; whereas I will not score a 1600 the next time I take the SAT test is an internal negation. The difference between the two claims can be seen as follows: if it is presently undetermined whether or not I score a 1600 the next time I take the SAT test (i.e. my scoring 1600 is consistent with all present truths and my not scoring a 1600 is also consistent with all present truths), then I will score a 1600 the next time I take the SAT test is false but so is I will not score a 1600 the next time I take the SAT test. If it is genuinely undetermined whether or not I will score a 1600 , the claim that I will achieve that score is false and so is the claim that I will not achieve that score. In other words, in the scenario just described It is not the case that I will score a 1600 the next time I take the SAT test is true but I will not score a 1600 the next time I take the SAT test is false. This shows that the former, the external negation, is not (logically) equivalent to the latter, the internal negation. As long as the distinction between internal and external negation is appreciated, one can affirm a sensible, restricted bivalence as involving external negations of claims and alongside it maintain the law of excluded middle (every proposition is either true or not true/false) and the 
law of non-contradiction (no proposition is both true and not true/ false). In order to appreciate the distinction just highlighted, one ought to affirm bivalence only in this restricted sense.

Now, since there are propositions that concern all possible future states of affairs, it follows from unrestricted bivalence that all (logically possible) future states of affairs either will obtain, or will not obtain. For example, right now, either it is true that I will fall asleep at 11:17 p.m. this evening or it is true that I will not fall asleep at 11:17 p.m. this evening. At this point, an interesting question arises: does this in turn mean that it is now either necessary or impossible that I fall asleep at 11:17 p.m. this evening? I think we often have mixed feelings here- or at least we did before we came to a firm philosophical position on the matter. On the one hand, it seems that if we take the claim that a proposition about the future is true seriously, not confusing it with the claim that the proposition is likely true or the claim that some wise individual (or individuals) think it is true, then there is simply no other way the world (this world) can go. What is true cannot become false; hence what is true is logically fixed, or necessarily true. On the other hand, we suspect that in the reasoning just mentioned we are somehow confusing truth with necessity (and falsity with impossibility); that a proposition is true does not imply the stronger claim that it is necessary, even if it somehow seems that way. Philosophers have debated such points throughout the history of philosophy, and continue to do so today. As with most disagreements, much of the disagreement is merely verbal- and some of it is not. In this article, I will try to distinguish the disagreement that is merely verbal from the deeper philosophical disagreement. In particular, I hope to show that we should all agree that all propositions about the actual world are (now) either necessary or impossible if unrestricted bivalence holds, while admitting that propositions not (only, or explicitly) about the actual world may be contingent, even under the assumption of unrestricted bivalence. Put another way, I hope to show that all propositions (including those about the future) are either necessary in the actual world or impossible in the actual world-again if we grant unrestricted bivalence. I will then argue that possibility in the actual world, rather than any other type of possibility, is the modal 
concept that is required for our powers, abilities (to do otherwise), and control. In short, unrestricted bivalence implies that no one is able to do otherwise than she does, no one has the power to do anything other than she does, and no one is in control of what she does. This point is quite significant when combined with so-called principle of alternate possibilities, which states that without the ability to do otherwise, no one is free or morally responsible for her actions.'

\section{Sketching the Argument}

The following is the exact argument I want to defend:

1) It is true (at $\left.t_{0}\right)$ that $x$ does $y$ at $t_{1}{ }^{2}$ (assumption)

2) It is true (at $t_{0}$ ) that $x$ does $y$ at $t_{1}$ in the actual world. (from 1)

3) It is necessary (at $t_{0}$ ) that $x$ does $y$ at $t_{1}$ in the actual world. In other words, in/from all (at $t_{0}$ ) possible worlds, $\mathrm{x}$ does $\mathrm{y}$ at $\mathrm{t}_{1}$ in the actual world. (from 2)

4) $X$ is not able to do otherwise than $y$ at $t_{1} ; x$ does not have the power at $\mathrm{t}_{0}$ to not do $\mathrm{y}$ at $\mathrm{t}_{1}$ (a.k.a. refrain from doing $\mathrm{y}$ at $\mathrm{t}_{1}$ ); $\mathrm{x}$ does not at $\mathrm{t}_{0}$ have under her control whether or not she does $\mathrm{y}$ at $\mathrm{t} 1$. (from 3$)$

5) $\mathrm{X}$ is not free, or morally responsible, in regards to whether or not she does $y$ at $t_{1}$. (from 4 )

I have given the stronger, more general argument, but to focus on my target, let $t_{0}$ be now and $t_{1}$ some time in the future. Then we are talking about future time facts. Then the argument shows that if it is now true that $x$ does $y$ at some time in the future, it is now necessary that $\mathrm{x}$ does $\mathrm{y}$ at that (future) time in the actual world. In other words, it is now impossible that $\mathrm{x}$ does not do $\mathrm{y}$ at that (future) time in the actual world. ${ }^{3}$ In other words, I am arguing that if we accept unrestricted bivalence (which I do not think we should), we get that for everything we do in the future, nothing 
else was ever possible-in the actual world, that is. I then argue that this excludes our control/ability to do otherwise-and hence our freedom and moral responsibility. Note that a parallel argument shows that if it is previously true that $x$ does not do $y$ at $t$, then it is at that previous time necessary that $x$ not do $y$ at $t_{1}$ in the actual world (i.e. it is at that time impossible that $x$ does $y$ at $t_{1}$ in the actual world)- and ultimately that $x$ is not morally responsible for not doing $\mathrm{y}$ at $\mathrm{t}$.

To be a little more specific, let to be the moment of one's birth, let $t_{1}$ variously refer to all the different times of one's future life, and let y variously refer to different possible actions one might take, or life choices one might make, significant and insignificant alike. By the argument just sketched (and unrestricted bivalence), even then, at the moment of one's birth, it is not possible that one act in any other way (in the actual world) than one winds up acting throughout one's entire life. If at the moment of one's birth it is not possible (in the actual world) that one act other than one (supposedly) will throughout one's life, then nowhere later could it be possible that one act differently than one does. An opponent can reject the very last inference, and it will leave my argument untouched- again, just run the argument separately for every moment of one's life. In other words, using the assumption, 1), let to refer individually to all the different moments at which one exists; if the argument is sound, then there is no moment at which one can act differently than one has acted, is acting, or will act (again, assuming we grant unrestricted bivalence). I proceed to argue that one can conclude that there is correspondingly no moment where one has control over her actions (or freedom and moral responsibility for the said actions). As is emphasized above and will be made more explicit, I am not challenging the traditional modal logic framework, but rather I am highlighting a specific modal notion, which is aptly called possibility in the actual world.

\section{Defending the Argument}

Now let me briefly elaborate upon and defend each of the claims/steps in the argument above: 
Step One: This is the sole hypothesis or premise in question. The succeeding steps follow, in the order suggested, culminating with the conclusion, 5).

Step Two: This either follows from, or is equivalent to, 1). At least on standard accounts, saying $x$ does $y$ at $t_{l}$ is tantamount to saying $x$ does $y$ at $t_{1}$ in the actual world. In any case, interesting future time facts (or, if my interlocutor insists, the ones I am interested in) concern what will happen in the actual world. This seems obvious, but some ambiguity lurks. Let me therefore say more about what I mean by 'the actual world'. Contrary to David Lewis's recommendation, I use 'the actual world' to rigidly designate, or uniquely identify, this world. ${ }^{4}$ I use 'the actual world' as a demonstrative. Even if one does not accept the claim that there is a truth about which expressions are rigid designators and which are not, one nevertheless ought to acknowledge that one may use a term as a rigid designator (along the lines Kripke explains), if one declares such and is clear and consistent about doing so.' In so doing, one is merely explaining what one means by her language. And what $I$ mean by 'the actual world' is the world in which you and I live, not, for example, our "twins" in a world extremely similar but not identical to ours. I mean this world, our world, with all of its particularities, its uniqueness, and its unknown characteristics. For at least most descriptions of the actual world, several "possible" worlds will meet this description. By 'the actual world', I do not mean a world that meets some description of this world that fails to uniquely identify it. If for some reason this is still not clear, try giving the actual world, our world, a name or a number- say, world 153. Then substitute 'world 153 ' for 'the actual world' in the argument sketched above and analyzed below. In any case, as I am using the expression, 'the actual world' refers to the same world in/from all possible worldsnamely ours!

But what exactly is our, this, or the actual world? By 'the actual world', I mean the world as defined by all that is presently true about the (this) world. Hence, the actual world at present may not include much of its future (i.e. may not include very many truths about the future). For example, it may be presently 
undetermined whether or not I go to bed at 11:04 p.m. tonight (i.e. it may not (now) be true that I will go to bed at 11:04 p.m. tonight but also not (now) true that I will not to bed at 11:04 p.m. tonight). ${ }^{6}$ In other words, nothing about the world right now implies exactly when I will go to bed tonight. Thus, when I go to bed tonight is in no sense a part of this world (the actual world) at present, but at best a part of what this world will be- though 'what this world will be' does not currently refer to anything (in particular) to the extent to which the future is undetermined (not implied) by what is presently the case. In any case, when I use 'the actual world', I mean only this world at present.

The idea of the future being undetermined should be rejected by anyone who affirms unrestricted bivalence, for if bivalence holds in an unqualified way, then all future possibilities (currently) either will obtain (in the actual world) or will not obtain (in the actual world), and correspondingly the entire future of the actual world holds, or obtains, now, in this world. I think that this is at least one reason why more philosophically standard usage lets a world be defined by an entire past, present, and future. Most philosophers and philosophical traditions sanction unrestricted bivalence; thus the most natural and complete way to define a world is as including its future as well as its past and present. However, one may want to hold out against unrestricted bivalence, since it ignores an important distinction (see section I). One may also want to hold out against unrestricted bivalence on the suspicion that it implies that we are not ever able to do otherwise, that we are not free, and that we are not deeply or morally responsible for any of our actions (I am attempting to ground this suspicion in this article).

Step Three: Just to be clear, I will explain why one cannot validly infer that a proposition is necessary (or that its contradictory is impossible) purely on the basis of the fact that it is true. Focusing again on our actions, we could have, at least in a very general sense/modality, done things differently that we did in the past; the world could have unfolded differently than it did. Some of us might have gone to college at another school. Looking forward, we can do any of a number of different things next Saturday, some of which we will not actually do. In other words, what we do next 
Saturday is not necessary but contingent. Alternatively, it is said that we do different things on Saturday in different possible worlds (or in different possible scenarios). But why do we say such things? Two possibilities come to mind. First of all, we say this because if our situation/surroundings were different-or we were different in terms of our motivations, knowledge, or abilities-our actions would correspondingly alter. Secondly, we may say this in the belief that we are free from causal determinism and so the future of the actual world is causally undetermined; hence, the (actual) future could turn out in a number of different ways. Either explanation at least seems to support the claim that lots of options about our actions today were possible in our past, and lots of options are today possible about our future plans and actions. More formally, philosophers say that in other possible worlds, we do things other than what we actually do (do in the actual world). Examples that illustrate this idea include the following: it is true that I will play basketball on Wednesday but possible that I will not; the Lakers will win the NBA championship again in 2002 but it is possible that they will not; though I did decide to buy a kayak, it was possible that I did not decide to buy one. I must admit that I am suspicious of such claims, particularly the first two (futuredirected) claims, but I hope I have captured above how/why such claims are made.

In any case, the situation is altogether different with the 'in the actual world' qualification. Here the question is whether $x$ does $y$ at $t_{l}$ in the actual world entails that $x$ does $y$ at $t_{1}$ in the actual world is necessary (i.e. that $x$ does not do $y$ at $t_{l}$ in the actual world is impossible). To be more exact, is it the case that at whatever points in time $x$ does $y$ at $t 1$ in the actual world is true, $x$ does y at $t_{1}$ in the actual world is necessary, or necessarily true, as well? As I have explained, when I (and perhaps the reader as well) use 'the actual world', I (we) mean rigidly this world, our world, the world in which we all live with its past and present, and to the extent it already is fixed, or a part of this world, its future. The actual world is, again, not a world identical to this (the actual) world in some set of respects/characteristics, but the one and only world which is strictly identical to this one. Taking note of this, it is rather clear that the inference in question is valid. If it is true 
that $x$ does $y$ at $t$ in the actual world, it follows that it is necessary that $x$ does $y$ at $t 1$ in the actual world. Why? Quite simply because, granted the assumption, the (actual) world would contain a contradiction if $x$ did not do $y$ at $t 1$ in the actual world. Since $x$ not doing $y$ at $t_{1}$ in the actual world would produce a contradiction, it is impossible! $X$ not doing $y$ at $t 1$ in some other world would not produce a contradiction, but $\mathrm{x}$ not doing $\mathrm{y}$ at $\mathrm{t} 1$ in the actual world obviously would. Sure, one could discharge the assumption (and recourse to $\mathrm{x}$ doing $\mathrm{y}$ at $\mathrm{t} \mathrm{t}$ in some distinct and incompatible world), but that would not prove anything. The question is whether or not the premise can be true and the conclusion false at the same time. That cannot be.

This point can be made a bit more formally as well. Consider the possible worlds framework: what is possible is what occurs (or is true) in at least one possible world, and what is necessary occurs in all possible worlds. For it to be necessary that $x$ does $y$ at $t_{1}$ in the actual world, this proposition would have to be true in/ from all possible worlds. Is it true that $x$ does $y$ at $t_{1}$ in the actual world in/from other possible worlds? Presumably, in many worlds, $\mathrm{x}$ does not do $\mathrm{y}$ at $\mathrm{t}_{1}$ - but there is no world where it is true that $x$ does not do y at $t_{1}$ in the actual world. This assumes the singularity of reference of 'the actual world', but I have made it clear that this is how I am using the language and what is at issue. Consider calling the actual world world 153 here again. If it is true that $x$ does $y$ at $t_{l}$ in world 153, then it is true that $x$ does $y$ at $t_{1}$ in the world 153 in/from all other possible worlds (e.g. worlds 1-152, world 154 , and so on).

I think this explains some of our ambivalence about whether or not the claim that it is now true that some future event will occur implies claims like the following: this event's occurring is the only way things can go, it is already fixed that this will happen, and the like. In a sense these things do follow: there is correspondingly only one way things can go in the actual world. In another sense these things do not follow: in other possible worlds that are very similar to the actual world, things go differently. The latter observation leads many philosophers to claim that things therefore could have gone differently. Sometimes, such philosophers even claim, paradoxically and dubiously, that things 
therefore could have gone differently in the actual world. However, we have just seen the deep problems with claiming the latter (while using 'the actual world' as a rigid designator).

Step Four: Until this point, it may have appeared that my argument here is merely verbal; it may appear that the argument at hand is merely an argument over who owns the expression 'possibility in the actual world'. I think the disagreement here is much more than a verbal dispute, as is seen first of all by considering whether 4) follows from 3). In other words, what sense of possibility (or "the way things can go") is the sense that is relevant to our powers, abilities, and control-and ultimately to our freedom and responsibility? To answer this, we should get clearer on the notion of possibility in the actual world, and on other modal notions that might instead be relevant to one's powers, abilities, and control. I will now survey three different types of modal notions in an attempt to address this question.

\section{Historical Possibility/ Possibility in the Actual World}

Possibility in the actual world is a relatively clear notion: we have seen that nothing which contradicts what is (now) true in the actual world is (now) possible in the actual world, but there is no basis for excluding anything else from being possible in the actual world. In other words, a proposition is possible in the actual world (at t) if and only if it is consistent with all the truths of the world (at t).' Applying this to the case of one's possible future actions, we get the following: a proposed future act, or a proposition about the future, is possible in the actual world if and only if the relevant action (proposition) is consistent with all the current truths of the world. What is currently true about the world presumably includes the laws (of nature), which allow one to connect causes with their effects, as well as truths about the future to the extent that there are currently such truths. One might alternatively call this notion historical possibility since it is indexed to a time, or is based quite literally on what is now (at this point in history) true of the actual world.

Is possibility in the actual world/historical possibility the type of possibility required for agent's having powers and abilities to 
do otherwise? Indeed it is: one's being able to commit a given action (in the actual world!) requires that the action be possible in the actual world, or historically possible. Since the past and present are fixed, no one is able to change the past or the present nor is anyone able to do anything that contradicts past and present truths. Put another way, no one has the power to do anything that contradicts past and present truths. Since control is typically construed as requiring a bi-directional ability or power, one can add that a proposed future action is under one's control only if the act and its contradictory are both possible in the actual world (i.e. only if both are individually consistent with the complete current description of the world, with the set of all currently true propositions about the world).

\section{Logical (Ahistorical) Possibility}

One notion of possibility that is very different than possibility in the actual world is logical possibility. Let us say that some proposition is logically possible if and only if there is a logically consistent description of the (a) world in which the proposition is true.' Logical possibility is obviously a coherent and internally consistent notion, and indeed useful in many reflections. Is logical possibility the sense of possibility relevant to what we can do, to questions of our powers and abilities? I think it is clear that logical possibility is far too loose to be the modal notion that is required to justify claims of power, ability, and control.

The following are just a few counterexamples that one might propose to challenge the claim that logical possibility is the modal notion we are looking for here. It is logically possible that first president of the United States was Bozo the clown. It is also logically possible that one died yesterday-right now as one lives and breathes today! Perhaps at some time in the past there were agents who had the powers and abilities to make these things happen (or have happened), but surely no one does today. It is also logically possible that I run a sub-five minute mile tomorrow, even though I assure you that such is inconsistent with my fitness level and running ability-and any track on Earth! Correspondingly, running a sub-five minute mile is not something 
I am able to do, or something within my power (certainly tomorrow, and probably ever). It is clear that at least some past and present truths constrain what is within one's powers and abilities, as well as what is under one's control. Hence, more than mere logical possibility is required for an action to be under our control or within our powers and abilities.

\section{Partial Historical Possibility}

Many philosophers largely accept the claim that the past is fixed or unchangeable, but at the same time argue for the compatibility of future time facts/unrestricted bivalence and our powers and abilities to do otherwise. For these philosophers, certain past (and present) true propositions are not fixed, or at least are not restrictive of future possibilities. I describe such philosophers as holding a partial historical notion of possibility. Let us say that a proposition is partially historically possible if and only if it is consistent with a certain (proper) subset of the past and present truths. What this subset is varies with the particular partial historical account.

William Ockham is a classic example of a philosopher who upholds a partial historical notion of possibility. ${ }^{10}$ Ockham and his followers hold that propositions purely about the past do restrict future possibilities and are (now) all either necessary or impossible. For example, on their view 'Bill Clinton was the President of the United States in 1998' is now necessary and 'Airplanes started mysteriously falling from the sky on January 1, 2000' is now impossible. Any proposition inconsistent with a (true) proposition purely about the past will not be admitted as possible by an Ockhamist. On the other hand, on the Ockhamist view propositions in part about the future are in most cases contingent (neither necessary nor impossible). For example, 'It is now true that I will eat bran flakes tomorrow' is contingent on the Ockhamist view. It is thus claimed that at least most propositions in part about the future are not restrictive of historical possibilities. This makes future time facts compatible with contrary possibilities, and, by implication, with contrary powers and abilities (with one's ability to do otherwise). 
However, partial historical possibility stops short of what is required for genuine powers, abilities (to do otherwise than one does), and control. Why? When one considers what type of possibility is relevant to one's powers and abilities, it is straightforwardly irrelevant happens in other worlds, as defined by a different set of true propositions (or what would happen if this world were different than it is). When one wonders about what one has the power or ability to do, one is not wondering what is consistent with a set of propositions, some of which are false, or a set of propositions that excludes certain true propositions. The number of false propositions is not the issue; a world with a single false proposition (i.e. a proposition now false in the actual world) is just as irrelevant to one's powers, abilities, and options as are worlds with hundreds of false propositions, for the contradicted or omitted proposition might be, and in the context likely is, the reason the option in question is being claimed as within the agent's power or ability. If it is now true that I will not go for a run tomorrow (not that it is unlikely that I will run tomorrow, or that some wise individual thinks I will not run tomorrow, or that the relevant proposition will be true at some later point), it seems to straightforwardly follow that, at least for me, in this world, I lack the power or ability to run tomorrow. After all, if I actually did run tomorrow (if I ran tomorrow in the actual world), the actual world would contain a contradiction. Surely the actual world cannot contain a contradiction, and perhaps even more surely $I$ do not have the power to make it so. One's doing $\mathrm{x}$ in a world characterized by a set of (true) propositions which is different than that of the actual world (at present) simply does not help support the claim that it is (now) in one's power to do $x$ (in the actual world!), nor does it help justify the claim that one is able to do $x$ (in the actual world). It is not that one cannot sensibly talk about such worlds or such possibilities; it is just that these worlds tell us nothing about our (current, this-world) abilities, our control, and our powers.

Step Five: This follows from 4), and natural definitions/ conceptions of freedom and (moral) responsibility. Most have a strong intuition that freedom and moral responsibility require an 
ability to do otherwise (and the related powers and control), although I must acknowledge that many disagree. I embrace the commonly held intuition that if an agent has no other choice, no other option, and/or no control over the outcome of her decisionmaking process or her behavior, she therefore does not act freely and bears no moral responsibility for what she does. If an action is really unavoidable or such that it could not fail to occur, it is not the responsibility of its agent; rather, the act is the responsibility of whatever circumstances or powers made it unavoidable, if anything at all. As I alluded to above, I do not deny that there are some conceptions of freedom and moral responsibility that do not require that one be capable of doing otherwise than one does, but I suggest that these conceptions of freedom and moral responsibility are weak and ultimately unsatisfying. Such conceptions do not capture what is interesting and important about us as decision makers and agents. It seems to me that accounts that deny that freedom and responsibility require an ability to do otherwise are too narrowly focused on the question of when it is practical to hold an individual responsible, and forget about the question of when it is fair or appropriate to hold an individual responsible, i.e. the question of when an individual deserves to be praised or blamed for her actions."

\section{An Example}

The following example helps illustrate the crucial argument, from 3) to 4) as outlined above. Consider a young college student wondering if he can solve all the proofs in his abstract algebra assignment before the next class, when the assignment is due. He wonders if it is in his power (within his reach) to solve them all, if it is under his control whether or not he solve them all, etc. What, exactly, would support the claim that he has such in his poweror that he is able to do so? What would not support the student's being able to complete all the proofs and the like is that his completing all of them is consistent with some partially false or incomplete (at the time of his inquiry) set of truths. In other words, that it is possible in a logical/ahistorical, or only partially historical, sense of possibility that he complete them all does not 
justify the relevant claims of powers and abilities here. For example, if he had begun the proofs earlier (when he hasn't), or if he were a little more creative (than he is at the time), or if the proofs were a little easier (than they are), or if he were a little more diligent (than he is at the time), or if it were not true that he will fail to complete them all (though it is true), then, let's say, he would, or could, have completed all the proofs. Or say that if one ignores the fact that he has the exact level of diligence and creativity he does, or the fact that it is now (already) true that he will not complete all the proofs, then there is a corresponding complete and comprehensive story (world) in which he completes all the proofs. Do any of these observations support the claim that it is in his power, or under his control, that he completes all the proofs? I think it is clear that these observations do not help establish the said abilities and powers.

Rather, for him to have the ability to complete all the proofs, his doing so must be consistent with all the present and past truths of the actual world ( $h$ is world), at the time of inquiry concerning possibility- including his creative and intellectual talents, his diligence, the time he began working, the particularities of his surroundings, and future time facts (that are then true). For him to have the ability to complete all the proofs, it must be possible for him, here, in this world to complete them all; i.e. his completing all the proofs must be possible in the actual world. Such consistency (with the actual world at the relevant time) is necessary for the student to have the said powers, or to have the said possibilities within his reach or under his control. We may put this a bit more technically as follows: completing all the proofs is under the student's control at $t$ only if both completing all the proofs and not completing all the proofs are (individually) consistent with all that is true about the actual world at $t$ (i.e. his completing all the proofs and his not completing all the proofs are both possible in the actual world at $\mathrm{t}$ ).

\section{Conclusion}

In sum, I contend that there is overwhelming reason to say that possibility in either an ahistorical/logical or a partial historical 
sense is not the sense of possibility that is required for one to be able to do otherwise, and to have power and control over her actions. Partial historical notions (in the radical case ahistorical notions) of possibility recognize only part of presently true propositions as restrictive of future possibilities, thus ignoring many of the very truths that clearly exclude the possibility of our acting in various ways- in the actual world, of course. The sense of possibility required for one's powers, abilities, and control over her actions is more restrictive than even partial historical possibility; the restriction that must be made is consistency with all that is currently true, including the presently true laws, which connect propositions with one another, or causes with their effects. ${ }^{12}$

I have therefore characterized the modal concept that is required for our abilities, powers, and control- and ultimately our freedom and responsibility- as being consistent with all present truths and called it possibility in the actual world. We have good reason to uphold the inference from the necessity in the actual world of an action (or the impossibility in the actual world of its contradictory) to the relevant agent's inability to do otherwise (the inference from 3) to 4) in the argument sketched at the outset of this article), for we have shown that any partial historical modal notion fails, that anything short of (weaker than) possibility in the actual world is not restrictive enough to be the modal concept required for one's powers, abilities, and control. Hence, the only recourse for the philosopher who wants to uphold the compatibility of unrestricted bivalence and freedom/responsibility is to insist that freedom and responsibility do not require the ability or power to do otherwise, i.e. to object to the inference from 4) to 5) in the argument I have sketched. However, many philosophers have made a strong case that this inference is in fact legitimate.

\section{Notes}

${ }^{1}$ I argued for the principle of alternate possibilities and addressed Harry Frankfurt's alleged counterexamples to the principle in another article.

${ }^{2}$ One who believes that propositions never become true or false as time goes by will find my parenthetical qualifications a bit odd, or, better, 
unnecessary stipulations. However, it is unfair to object to the argument to come simply because its locutions are unnecessarily specific. Furthermore, I ask the interlocutor who is suspicious in this way to simply ignore the at $t_{0}$ qualification. The argument is still sound.

3 Or, one could put it in these terms: it is now necessary in the actual world that $\mathrm{x}$ does $\mathrm{y}$ at $\mathrm{t}_{1}$ and impossible in the actual world that $\mathrm{x}$ does not do $y$ at $t 1$.

${ }^{4}$ See Lewis, D. 1986. On The Plurality of Worlds. Cambridge, MA: Blackwell Publishers, especially pp. 92-96.

5 See Kripke, S. 1972. Naming and Necessity. Cambridge, MA: Harvard University Press.

${ }^{6}$ Granted, it is true that I will go to bed at 11:04 p.m. tonight or it is not true that I will go to bed at 11:04 p.m. tonight even in the scenario I am suggesting-it is not true that I will go to bed at 11:04 p.m. tonight in this scenario. However, it is not true that I will not go to bed at 11:04 p.m. tonight either. Bear in mind that the latter is not to say that I will go to bed at 11:04 p.m. tonight, so long as we appreciate the distinction between internal and external negation. Again, see section $I$.

${ }^{7}$ I take it that if a proposition is true at some time $t$, then it is true that is (was) true then at all later times. In other words, if $p$ is true at $t_{1}$, then $p$ is (was) true at $t_{I}$ is true at all times $t$, where $t$ is after $t_{l}$. For example, if it true that many persons are scared of $Y 2 K$ in 1999 , then in all years later than 1999, it is true that many persons are (were, we say) scared of Y2K in 1999. So long as the time index is already (implicitly or explicitly) in $p$, we can simply infer from $p$ 's being true (at $t_{1}$ ) that $p$ is true at all later times t. A case of an explicit time index would be the proposition, Mark $M^{C}$ Guire broke the home run record in 1998. There are also many cases where the time index of a proposition is merely implicit (e.g. whenever one speaks in the present tense without noting the relevant present time). For example, the proposition George W. Bush is the President of the United States is now true but will not (as such) be true in 3001. However, if one takes the implicit time index into account, the proposition just mentioned is more exactly captured as George $W$. Bush is the President of the United States in 2001, and that proposition is true at all times in the future. Hence, in saying that what is appropriately deemed possible is what is consistent with all present truths, one is saying that what is appropriately deemed possible is what is consistent with all present and past truths- since all that was true in the past, when appropriately indexed to the past, is true in the present.

$8 \mathrm{I}$ use 'only if' here rather than the biconditional since I hold that possibility in the actual world is a necessary but not a sufficient condition for an act which an agent is in control of, has in her power, etc. Roughly 
speaking, the further necessary condition is that a relevant undetermined event/proposition directly involves the agent rather than something outside of her. For freedom and moral responsibility, as opposed to (mere) powers and abilities, I believe some additional conditions are required as well. These additional conditions include, importantly, a certain understanding of the different options and a genuine effort to make the right choice.

${ }^{9}$ Somewhat different notions may be carved out by additional constraints besides logical consistency. For example, one may insist that the laws of nature and/or certain metaphysical truths be the same in all "possible" worlds as they are in the actual world.

${ }^{10}$ See, for example, Ockham, William. 1983. Predestination, God's Foreknowledge, and Future Contingents. trans. M. $\mathrm{M}^{\mathrm{c}} \mathrm{Cord}$ Adams and N. Kretzmann. Indianapolis, IN: Hackett Publishers. Luis de Molina offers an interesting variant on the partial historical approach to possibility (and powers and abilities), claiming that non-causal past and present truths do not restrict agents' possibilities, powers, and abilities. Noncausal truths include the types of future time facts just mentioned. Molina's account is implausible for essentially the same reasons I will cover with respect to Ockham. See De Molina, Luis. 1988. On Divine Foreknowledge. trans. A.J. Freddoso. Ithaca, NY: Cornell University Press.

${ }^{11}$ Harry Frankfurt has offered a famous objection to the inference from 4) to 5), which I have addressed in a separate article.

12 The laws must be presently true for them to restrict possibilities, or freedom and control. If the laws are true only once the world's history is complete, they do not plausibly restrain our actions or threaten our (current) powers and abilities. As van Inwagen argues, such "laws" are not really laws at all. See Van Inwagen, P. 1982. The Incompatibility of Free Will and Determinism. In Free Will, ed. G. Watson, 46-58. New York: Oxford University Press. 